\title{
A broad-host range coliphage against a clinically isolated E. coli O157: isolation and characterization
}

\author{
Abdollah Ghasemian ${ }^{1,2}$, Maryam Bavand ${ }^{2}$, Zahra Moradpour ${ }^{1 *}$ \\ ${ }^{1}$ Department of Pharmaceutical Biotechnology, Faculty of Pharmacy, Urmia University of Medical Sciences, P.O. Box 57157-1441, Urmia, Iran. \\ ${ }^{2}$ Department of Pharmaceutical Biotechnology and Pharmaceutical Sciences Research Center, Faculty of Pharmacy, Shiraz University of Medical Sciences, \\ P.O. Box 71345-1583, Shiraz, Iran.
}

\section{ARTICLE INFO \\ Article history: \\ Received on: 10/10/2016 \\ Accepted on: 15/12/2016 \\ Available online: 30/03/2017}

Key words:

Bacteriophage, E. coli O157,

antibiotic resistance, phage

therapy, siphoviridae.

\begin{abstract}
Escherichia coli $\mathrm{O} 157$ is one of the common and problematic pathogens, particularly in developing countries. To isolate a phage against this pathogen, a total of 32 water samples were enriched for phage and two of these samples were found to contain lytic phages that grow on and kill enterohaemorrhagic E. coli serotype O157. Following the primary evaluation, the most efficient phage was chosen for further characterization. The multiplicity of infection, morphology, killing efficiency and bacterial host range were determined under controlled conditions in the laboratory. Isolated phage was designated gBSN-MGB13. According to transmission electron microscopy, this lytic phage morphologically belonged to the myoviridae family. Based on phage efficiency test, a multiplicity of infection of $5 \mathrm{logs}$ of gBSN-MGB13 resulted in $50 \%$ reduction in viable bacterial cell count after $20 \mathrm{~min}$ incubation in $37{ }^{\circ} \mathrm{C}$ without shaking. Since gBSN-MGB13 is a broadhost range phage and effective against several pathogenic species, E. coli $\mathrm{O} 157$ as well as Proteus vulgaris and Pseudomonas aeruginosa, its applications could be investigated in complex infections as combinatory therapy. This is an exciting aspect of phage therapy.
\end{abstract}

\section{INTRODUCTION}

Over the last years, despite the strict controls to prevent food born diseases; enterohaemorrhagic Escherichia coli (E. coli) E. coli (EHEC) serogroup $\mathrm{O} 157$ has emerged as a worldwide threat to public health following its first identification in an outbreak occurred by year 1982, when the illness was associated with the consumption of undercooked ground beef (Aslantas et al., 2006; Dontorou et al., 2003). According to the U.S. center for disease control and prevention (CDC), E. coli $\mathrm{O} 157$ is still an important cause of human illness in the United States and CDC reports multistate outbreaks of $E$. coli $\mathrm{O} 157$ regularly in which one of the last cases was in 2014 (Centers for Disease Control and Prevention, 2014). This food-borne pathogen is the reason of

\footnotetext{
* Corresponding Author

Zahra Moradpour, Department of Pharmaceutical Biotechnology, Faculty of Pharmacy, Urmia University of Medical Sciences, P.O. Box 57157-1441,Urmia, Iran.Email: zahramoradpour @ gmail.com
}

human illness varies from self-limited watery diarrhea and hemorrhagic colitis to critical manifestations such as the hemolytic uremic syndrome and thrombotic thrombocytopenic purpura (Boyce et al., 1995). E. coli is usually found in intestinal tracts of human and animals. Cattle and sheep are known to be the most important primary reservoirs for this human pathogen. Direct contact with animals, contaminated drinking or swimming water, and person-to-person infections are important routes of transmission for sporadic human infections (Cornick and VuKhac, 2008; Gansheroff and O'Brien, 2000). CDC approximates that $E$. coli O157:H7 causes just about 73,400 illnesses and 60 deaths annually in the United States. Schroeder et al. (2002) pointed out that antibiotic resistant E. coli pose a growing threat. Phages are viruses that infect prokaryotes. Like all viruses, phages are obligate intracellular parasites, which have no intrinsic metabolism and need the metabolic machinery of the host cell to hold their reproduction. Bactericidal phages propose as a natural, nontoxic, feasible strategy for controlling several human pathogens. 
Phages control bacterial populations by infecting, killing and changing them by exerting evolutionary pressure on the host cell often specifically (Weber-Dabrowska et al., 2000; Yoichi et al., 2004). Although phages have originally been discovered since 1915, their potential application as an antibiotic alternative has been renowned only recently (Lorch, 1999).

Obviously, phages are an important part of the environmental ecosystem and are produced naturally at the universe (Karunasagar et al., 2007; Lorch, 1999). Isolating E. coli O157 infective phages from natural resource and testing their use to control E. coli $\mathrm{O} 157$ in vitro, have been done by various research groups (Kudva et al., 1999; O'Flynn et al., 2004; Viazis et al., 2011). The aim of our current study was isolation, identification and characterization of a lytic phage from environmental natural water recourse against $E$. coli 0157 . The isolated phage is broad-host range and can kill Bacillus subtilis, Proteus vulgaris and Pseudomonas aeruginosa, as well. This lytic phage can potentially be used in controlling these four pathogens.

\section{MATERIALS AND METHODS}

\section{Bacterial strains and culture conditions}

The enterohaemorrhagic E. coli O157 was used for the screening and assessment of phage titer. This strain was originally isolated in Iran and was obtained from reference laboratory of $\mathrm{Bu}$ Ali hospital. Also, bacterial species (Table 1) were used for determining the host range of phage. Bacterial cultures were grown in Luria-Bertani (LB) broth ( $1 \%$ peptone, $0.5 \%$ yeast extracts and $1 \% \mathrm{NaCl}, \mathrm{pH} 7.2$ ). Agar plate (1.5\% Agar) was used for growing $E$. coli O157. Cultivation was carried out by picking an isolated colony from streak LB agar plate, inoculating into LB broth allowing it to incubate at $37{ }^{\circ} \mathrm{C}$, under aerobic conditions with agitation of $120 \mathrm{rpm}$.

Table 1: Host range of phage gBSN-MGB13.

\begin{tabular}{lcc}
\hline \multicolumn{1}{c}{ Bacterial isolate } & PTCC $^{*}$ & $\begin{array}{c}\text { Plaque } \\
\text { formation }\end{array}$ \\
\hline E. coli O157 & Clinically isolated & + \\
Bacillus subtilis & 1023 & + \\
Proteus vulgaris & 1312 & + \\
Pseudomonas aeruginosa & 1074 & + \\
Salmonella typhi & 1609 & - \\
Staphylococcus aureus & 1112 & - \\
Escherichia coli & 1329 & - \\
Staphylococcus epidermophilus & 1114 & - \\
Shigella dysenteriae & 1188 & - \\
Vibrio cholera & 1611 & - \\
Shigella flexenari & 1234 & - \\
Streptococcus pyogenes & 1447 & - \\
Bacillus stearothermophilus & 1353 & - \\
*PTCC: Persian Type Culture Collection & & - \\
\hline
\end{tabular}

\section{Phage isolation, propagation, and titration}

To isolate E. coli 0157 specific phages, 32 water samples were collected from natural water resources of Iran in 2011 to 2012 (Table 2). Samples were collected in sterile $15 \mathrm{~mL}$ tubes and shipped to the laboratory in $24 \mathrm{~h}$. Subsequently, the samples were centrifuged at $6000 \mathrm{rpm}$ for $20 \mathrm{~min}$, and the supernatants were filtrated through a $0.22 \mu \mathrm{m}$ pore-size filter. The filtrate was incubated at $37^{\circ} \mathrm{C}$ with an exponential growth-phase culture of E. coli $\mathrm{O} 157\left(\sim 10^{8} \mathrm{CFU} / \mathrm{mL}\right)$.

Table 2: List of sampling locations of natural water samples were collected for phage enrichment and isolation.

\begin{tabular}{|c|c|c|}
\hline $\begin{array}{c}\text { Sample } \\
\text { No. }\end{array}$ & Site- City & $\begin{array}{c}\text { Lysis on } E \text {. coli } \\
0157\end{array}$ \\
\hline 1 & Talar river- Bahmanmir & - \\
\hline 2 & Shazdeh river- Babolsar & - \\
\hline 3 & Babol river- Babolsar & - \\
\hline 4 & Fereidonkenar river- Fereidonkenar & - \\
\hline 5 & Sorkh river- Sorkhroud & - \\
\hline 6 & Vaghfi river- Mahmoudabad & - \\
\hline 7 & Kheshtsar river- Kheshsar & - \\
\hline 8 & Nour river- Nour & - \\
\hline 9 & Royan river- Royan & - \\
\hline 10 & Keshmeh- Nour & - \\
\hline 11 & Vazivar- North of Iran & - \\
\hline 12 & Kheir river- Nowshahr & + \\
\hline 13 & Nowshahr river- Nowshahr & + \\
\hline 14 & Chalous river- Chalous & - \\
\hline 15 & Haj river- Hajroud & - \\
\hline 16 & Beach-Sari & - \\
\hline 17 & Beach- Kish Island & - \\
\hline 18 & Beach- Persian Gulf & - \\
\hline 19 & Kalarabad river- Kelarabad & - \\
\hline 20 & Salmanshahr river-Salmanshahr & - \\
\hline 21 & Abbasabad river- Abbasabad & - \\
\hline 22 & Nashtarour river- Nashtaroud & - \\
\hline 23 & Shiroud river- Shiroud & - \\
\hline 24 & Chakroud river- Chakroud & - \\
\hline 25 & Ramsar river- Ramsar & - \\
\hline 26 & Kileh river- Tonekabon & - \\
\hline 27 & Haraz river- Amol & - \\
\hline 28 & Tajan river- Sari & - \\
\hline 29 & Siahroud river- Ghaemshahr & - \\
\hline 30 & Neka river- Neka & - \\
\hline 31 & Behshahr river- Behshahr & - \\
\hline 32 & A well-Ghaemshahr & - \\
\hline
\end{tabular}

After overnight shaking (120 rpm), debris and bacteria were removed by centrifugation at $6000 \mathrm{rpm}$ for $20 \mathrm{~min}$. Following this enrichment procedure, the supernatants were filtered through $0.22 \mu \mathrm{m}$ pore-size filter and analyzed by plaque assay on E. coli $\mathrm{O} 157$ using double agar layered method of Adams (Van Helvoort, 1992). The single plaques formed on the plates were stabbed with a needle and eluted with a small volume of phage buffer. Each phage suspension was serially propagated twice on the same strain. The most efficient phage with lytic (clear) plaques was selected for further study in our work and designated gBSN-MGB13. The corresponding location for selected phage was a river in Nowshahr city of Iran. Isolated phage was incubated with an exponential growth-phase culture of $E$. coli O157 for $20 \mathrm{~min}$ without agitating, and then with shaking (120rpm) until visible lysis was begun. The phage titer of $10^{12}$ $\mathrm{PFU} / \mathrm{mL}$ was obtained from this step. The lysate was centrifuged at $6000 \mathrm{rpm}$ for $20 \mathrm{~min}$. $\mathrm{NaCl}$ and PEG8000 were added to the supernatant to reach the final concentration of $0.5 \mathrm{M}$ and $20 \%$ $(\mathrm{v} / \mathrm{v})$, respectively and phage particles were precipitated at $4{ }^{\circ} \mathrm{C}$ overnight. The phage pellet was dissolved in SM buffer $(0.05 \%$ $\mathrm{NaCl}, 0.2 \% \quad \mathrm{MgSO}_{4} \cdot 7 \mathrm{H}_{2} \mathrm{O}, 0.005 \mathrm{M}$ Tris- $\mathrm{HCl}, \mathrm{pH} 7.5$ ) (Van Helvoort, 1992). In addition, phage activity in the supernatant was 
evaluated by a spot assay that entailed placing $5 \mu \mathrm{l}$ of the supernatant on LB agar seeded with $E$. coli $\mathrm{O} 157$. The plates were checked for plaque formation after overnight incubation at $37^{\circ} \mathrm{C}$ (Sheng et al., 2006).

\section{Determination of the host range of phage gBSN-MGB13}

Isolated phage was tested for its ability to form plaque on a range of gram-positive and gram-negative bacterial species (Table 1). The sensitivity of each bacterial species to E. coli O157infective phage was determined using the spot assay, as described above. The presence of a lytic zone was considered evidence of phage susceptibility, no cell lysis was considered a negative response indicating bacterial resistance to phage (Sheng et al., 2006).

\section{Determination of phage optimal MOI}

The optimal multiplicity of infection (MOI) for $E$. coli $\mathrm{O} 157$ was investigated by mixing and incubating bacteria and lytic phage at ratios ranging from $10^{-1}$ to $10^{5} \mathrm{PFU} / \mathrm{CFU}$ in tubes containing $10^{3} \mathrm{CFU} / \mathrm{mL}$ of $E$. coli $\mathrm{O} 157$. Mixtures were incubated for $20 \mathrm{~min}$ at $37{ }^{\circ} \mathrm{C}$. Phage-free cultures (containing only bacteria) and cell-free cultures (containing the only phage) were used as controls. Subsequently, the number of viable cells in mixtures was determined by plating on LB agar and incubating at $37{ }^{\circ} \mathrm{C}$ overnight.

\section{Killing efficiency of phage gBSN-MGB13}

Bacterial cells with $10^{3} \mathrm{CFU}$ were added with an equal volume of phage lysate $\left(10^{3} \mathrm{PFU} / \mathrm{mL}\right)$ at a multiciplity of infection (MOI) of 1. Phage-free E. coli culture was used as control sample in experiments. The mixtures were incubated at $37{ }^{\circ} \mathrm{C}$ for $9 \mathrm{~h}$. The optical density of test and control samples was recorded at $600 \mathrm{~nm}$ and was set zero at the time of infection. Spectrophotometric monitoring of bacterial growth in phage-free sample and the infected sample was carried out through viral lysis every $60 \mathrm{~min}$.

\section{Electron microscopy}

Pure, high-titer phage stocks were used. The sample was deposited on copper grids and allowed to adsorb for about one minute. Uranyl acetate (2\%) was used to stain the phage negatively for one minute. After the excess staining solution had been drained with filter paper, the grids were examined with an electron microscope (Philips, UK).

\section{Genome and proteome analysis of gBSN-MGB13}

Phage genome was extracted and purified from phage lysate using the phenol-chloroform method. The type of phage genome was examined by treatment with DNase I and RNase A. for restriction analysis, two enzymes were used (EcoRI and HindIII) which are added to phage nucleic acid using methods as recommended by the supplier. Treated nucleic acids were analyzed using $1 \%$ agarose gel. The phage proteins were analyzed using SDS-PAGE according to the Laemmli method (Laemmli, 1970).
Purified phage solution was precipitated with four volumes of icecold acetone. After centrifugation $\left(16,000 \times \mathrm{g} 20 \mathrm{~min}, 4{ }^{\circ} \mathrm{C}\right)$, the pellet was air-dried and re-suspended in the buffer. Briefly, $50 \mu \mathrm{L}$ of sample was added to $10 \mu \mathrm{L}$ of loading buffer and boiled for 10 min. The sample was then loaded on $12.5 \%$ SDS-PAGE slab gel and electrophoresed with Tris-glycine buffer.

\section{RESULTS AND DISCUSSION}

\section{Isolation and host range determination of phage gBSN- MGB13}

Screening tests for detection of lytic phages were performed with $E$. coli O157. Two samples from 32 collected water resources were active against the bacteria in the plaque assay. Each sample contained several phages. Through picking, reenriching and examining of clear plaques by plaque and drop assay, we found a lytic phage with remarkable lytic activity. Among the phage isolates, gBSN-MGB13 was more effective than the others at lysing E. coli O157. gBSN-MGB13 formed large clear plaques on the bacterial lawn (Fig. 1). To determine phage host range, gBSN-MGB13 was spot tested against 13 bacterial samples including gram positive and gram negative bacteria (Table 1). The results indicated that isolated phage has a lytic effect on 3 of 13 representative bacterial species as well as E. coli O157. gBSN-MGB13 produced plaques on Bacillus subtilis (B. subtilis), Proteus vulgaris ( $P$. vulgaris) and Pseudomonas aeroginosa ( $P$. aeroginosa). Therefore, it is concluded that this coliphage is polyvalent and not genus specific.

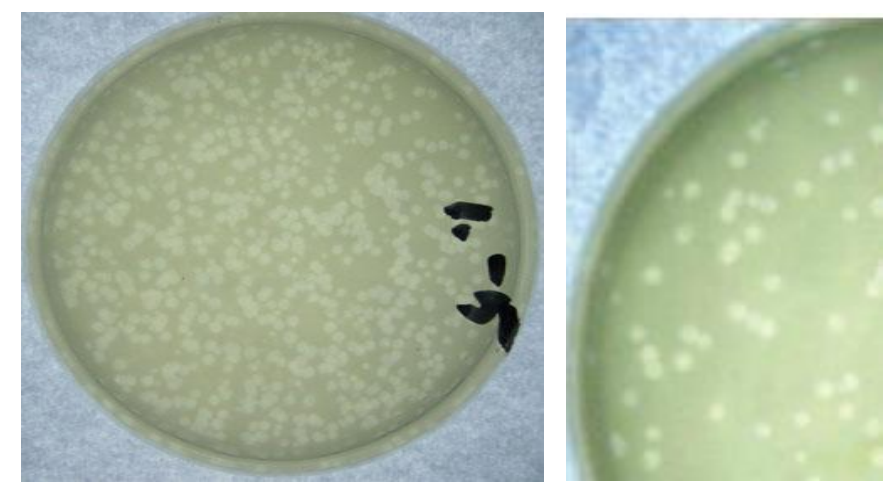

Fig 1: The plaque of gBSN-MGB13 using the double agar layered method on E. coli $\mathrm{O} 157$ lawn.

\section{Plaque size and morphology of phage gBSN-MGB13}

E. coli $\mathrm{O} 157$ lytic phage grew into clear plaques at $37^{\circ} \mathrm{C}$, with a plaque size of $3 \mathrm{~mm}$ in diameter (Fig. 1). An electron micrograph of isolated phage showed that it has a rather long tail (not long as siphoviridae and not short as podoviridae) and an isometric head (Fig. 2). gBSN-MGB13 morphologically belongs to the myoviridae family. Its length is approximately $130 \mathrm{~nm}$, and the head is about $50 \mathrm{~nm}$ in diameter. The plaque size of gBSNMGB13 (3 $\mathrm{mm}$ ) is relatively large comparing to previously isolated phages against $E$. coli $\mathrm{O} 157$ such as $\mathrm{KH} 1(<1 \mathrm{~mm})$ and SH1 (2 mm) (Sheng et al., 2006). There is no study investigating the relation between phage plaque size and its efficacy. 
Consequently it cannot be concluded that gBSN-MGB13 lyric effect against bacteria is superior to other isolated phages with the smaller size.

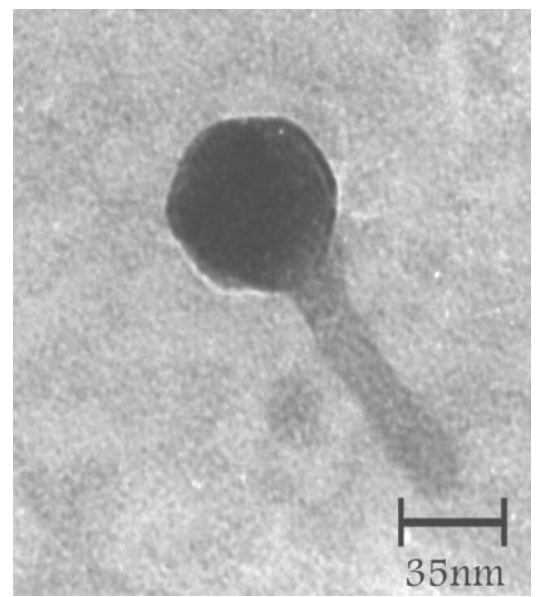

Fig 2: Electron micrographs of gBSN-MGB13 negatively stained with $2 \%$ uranyl acetate.

\section{Phage killing efficacy analysis}

To further characterize the isolated phage, different MOIs for the elimination of E. coli $\mathrm{O} 157$ were investigated. At MOIs ranging from $10^{-1}$ to $10^{5} \mathrm{PFU} / \mathrm{CFU}$, a reduction in bacterial titer was detected. At MOI of $10^{5} \mathrm{PFU} / \mathrm{CFU}, 50 \%$ bacterial growth inhibition relative to control samples without phage was observed in 20 minutes after infection. Phage gBSNMGB13 showed a strong activity against the bacterium. The time of action was really short and remarkable. According to other studies, in E. coli $\mathrm{O} 157$ culture-positive samples, phage treatments reduced the number of bacteria compared to untreated controls but did not eliminate the bacteria completely (O'Flynn et al., 2004; Tanji et al., 2005).

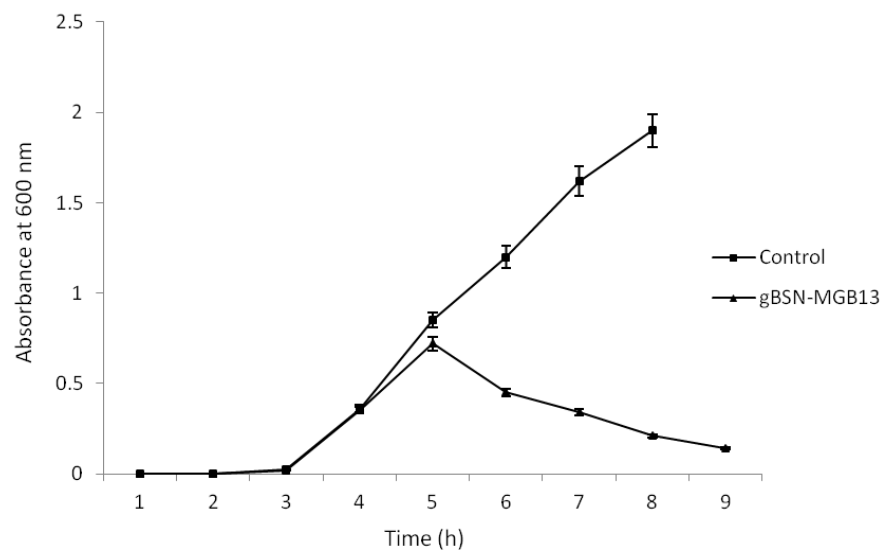

Fig 3: Killing efficiency of phage gBSN-MGB13. E. coli O157 cells were infected at the early log phase with phage lysate. Killing efficiency of phageinfected culture $(\diamond)$ and control culture (- $)$ were monitored spectrophotometrically.

Moreover, to determine the efficacy of phage on E. coli, the survival of bacteria was measured spectrophotometrically at MOI of 1 PFU/CFU (Fig. 3). Following four hours of the infection of bacterial cells with lytic phage, OD measurements of the control and test samples begin to diverge dramatically. At the $5^{\text {th }}$ hour, the curve of test sample dropped quickly indicating fast dying of bacteria regarding phage-free bacterial growth curve which showed a rising pattern. Based on OD-time curve in Fig. 3, the OD values of infected culture declined rapidly but did not reach to zero after nine hours of infection.

It is assumed that after infection, phage-bacteria culture reaches to a balanced state in which phages are not able to completely eliminate infected bacteria possibly due to mutations. Therefore, the initial rate of action decreases gradually hours after infection.

\section{Genome and proteome analysis of gBSN-MGB13}

The nucleic acid of the phage was extracted and subjected to enzymatic digestion analysis. The genomic nucleic acid of the phage was found to be a double stranded DNA following successful digestion with DNase I but not with RNase A. Treatment of the genome of gBSN-MGB13 with restriction enzymes EcoRI and HindIII were shown no bands on agarose gel electrophoresis (data not shown). This may probably due to the phage genome have no restriction sites for these enzymes, or the restriction sites have changed (by chemical modification) that EcoRI and HindIII cannot restrict the phage genome.

According to SDS-PAGE result, the protein composition of gBSN-MGB13 includes at least 8 distinct bands. The most predominant band could be accounted for major capsid protein which has a size of approximately $45 \mathrm{kDa}$ (Fig. 4).

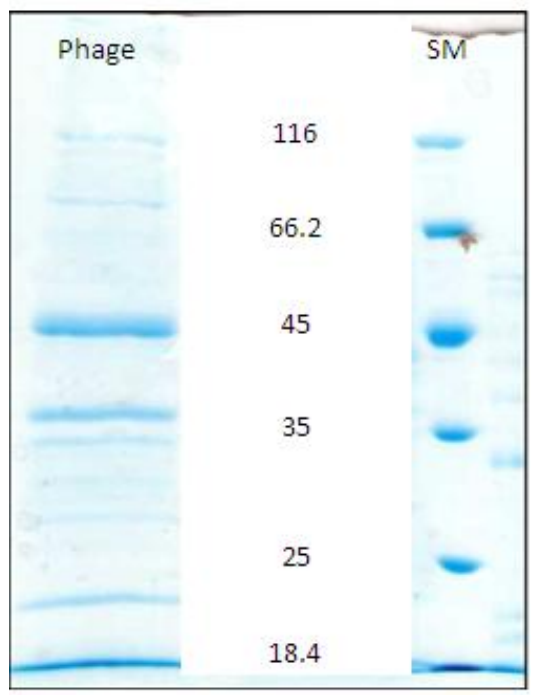

Fig 4: SDS-polyacrylamide gel electrophoresis analysis of phage gBSNMGB13. "Phage" is the phage proteins and "SM" is the protein size marker.

\section{CONCLUSION}

Treatment of $\mathrm{O} 157$ infection with antibiotics due to emerging resistant bacteria and increased expression of Shiga toxin genes is contraindicated (Igarashi et al., 1999; Proulx et al., 1992; Yoh and Honda, 1997). The risk of releasing Shiga toxin, thereby developing HUS (hemolytic uremic syndrome) is an 
undesirable side effect of antibiotics. Therefore, considering the above drawbacks and the relatively easy access to the natural water resources, phage therapy might be considered as an approach to apply in prevention and treatment of infectious diseases (Nakai and Park, 2002). Lytic phage therapy is one of the therapeutic alternatives for the control of E. coli O157 (Stevens et al., 2002).

Some studies have been carried out to assess the abilities of the phage to fight E. coli O157 (Bach et al., 2003; Kudva et al., 1999; Tanji et al., 2005).

In this regard, gBSN-MGB13 was isolated from water resources against $E$. coli $\mathrm{O} 157$ and was screened by spot testing against 13 different strains. Three other strains were sensitive to phage and gBSN-MGB13 formed clear plaques and was capable of lysing them (Table 1). Therefore, this potent lytic phage is not specific to $E$. coli O157. Since most bacterial infections do not have a clinical presentation that is specific enough to differentiate them from other acute bacterial infections and because broad-host range phages like gBSN-MGB13 are effective against several pathogenic species (in this case, E. coli $\mathrm{O} 157$ as well as Proteus vulgaris and Pseudomonas aeruginosa), their applications could be investigated in complex infections as combinatory therapy. This is an exciting aspect of phage therapy, particularly regarding that no adverse events related to phage application were reported following $E$. coli phage administration even by healthy adult volunteers received phage in their drinking water in other studies (Bruttin and Brussow, 2005).

There are some efforts to modify phages to more efficient forms and to address probable ecosystem considerations (Moradpour and Ghasemian, 2011; Moradpour et al., 2009). To improve the features of current phages and to modify them to meet the medical and regulatory requirements, it is essential to isolate new phages and explore detailed features of these isolates. This will motivate phage science toward developing new reliable biopharmaceuticals.

\section{ACKNOWLEDGMENT}

We thank the Bu Ali reference laboratory of Iran for providing of E. coli O157:H7.

Financial support and sponsorship: This work was supported by the Deputy of Research, Shiraz University of Medical Sciences, Shiraz, Iran (Grant no. 89-1-36-2527).

Conflict of Interests: There are no conflicts of interest.

\section{REFERENCES}

Aslantas O, Erdogan S, Cantekin Z, Gulacti I, Evrendilek, GA. Isolation and characterization of verocytotoxin-producing Escherichia coli O157 from Turkish cattle. Int J Food Microbiol, 2006; 106: 338-342.

Bach SJ, McAllister TA, Veira DM, Gannon V, Holley RA. (2003). Effect of bacteriophage DC22 on Escherichia coli O157:H7 in an artificial rumen system (Rusitec) and inoculated sheep. Anim Res, 2003; 52: $89-102$.
Boyce TG, Swerdlow DL, Griffin PM. (1995). Escherichia coli O157: H7 and the hemolytic-uremic syndrome. N Engl J Med, 1995; 333: 364-368.

Bruttin A, Brussow, H.. Human volunteers receiving Escherichia coli phage T4 orally: a safety test of phage therapy. Antimicrob Agents Chemother, 2005; 49: 2874-2878.

Centers for Disease Control and Prevention, C. 2014. Multistate Outbreak of Shiga toxin-producing Escherichia coli O157:H7 Infections Linked to Ground Beef. http://www.cdc.gov/ecoli/2014/O157H7-0514/index.html [Accessed June 20 2014].

Cornick, NA, VuKhac H. Indirect transmission of Escherichia coli O157: H7 occurs readily among swine but not among sheep. Appl Environ Microbiol, 2008; 74: 2488-2491. DOI: 10.1128/AEM.02897-07

Dontorou C, Papadopoulou C, Filioussis G, Economou V, Apostolou I, Zakkas G, Salamoura A, Kansouzidou A, Levidiotou S. Isolation of Escherichia coli $\mathrm{O} 157: \mathrm{H} 7$ from foods in Greece. Int J Food Microbiol, 2003; 82: 273-279.

Gansheroff LJ, O'Brien AD. Escherichia coli O157:H7 in beef cattle presented for slaughter in the US: higher prevalence rates than previously estimated. Proc Natl Acad Sci USA. 2000; 97: 2959-2961.

Igarashi T, Inatomi J, Wake A, Takamizawa M, Katayama $\mathrm{H}$, Iwata T. Failure of pre-diarrheal antibiotics to prevent hemolytic uremic syndrome in serologically proven Escherichia coli $\mathrm{O} 157: \mathrm{H} 7$ gastrointestinal infection. J Pediatr.1999; 135: 768-769.

Karunasagar I, Shivu MM, Girisha SK, Krohne G, Karunasagar I. Biocontrol of pathogens in shrimp hatcheries using bacteriophages. Aquaculture. 2007; 268: 288-292.

Kudva IT, Jelacic S, Tarr PI, Youderian P, Hovde CJ. Biocontrol of Escherichia coli O157 with O157-specific bacteriophages. Appl Environ Microbiol, 1999; 65: 3767-3773.

Laemmli, U.K. (1970). Cleavage of structural proteins during the assembly of the head of bacteriophage T4. Nature. 1970; 227: 680-685.

Lorch A. Bacteriophages: an alternative to antibiotics? Biotechnol Dev Monit. 1999; 39: 14-17.

Moradpour, Z., and Ghasemian, A. Modified phages: novel antimicrobial agents to combat infectious diseases. Biotech Adv.2011;29: 732-738.

Moradpour Z, Sepehrizadeh Z, Rahbarizadeh F, Ghasemian A, Yazdi MT, Shahverdi AR. Genetically engineered phage harbouring the lethal catabolite gene activator protein gene with an inducer-independent promoter for biocontrol of Escherichia coli. FEMS Microbiol Lett. 2009. 296: 67-71.

Nakai T, Park SC. Bacteriophage therapy of infectious diseases in aquaculture. Res Microbiol, 2002; 153: 13-18.

O'Flynn G, Ross R, Fitzgerald G, Coffey A. Evaluation of a cocktail of three bacteriophages for biocontrol of Escherichia coli O157:H7. Appl Environ Microbiol, 2004; 70: 3417.

Proulx F, Turgeon JP, Delage G, Lafleur L, Chicoine L. Randomized, controlled trial of antibiotic therapy for Escherichia coli O157:H7 enteritis. J Pediatr, 1992; 121: 299-303.

Schroeder CM, Zhao C, DebRoy C, Torcolini J, Zhao S, White DG, Wagner DD, McDermott PF, Walker RD, Meng J. (2002). Antimicrobial resistance of Escherichia coli $\mathrm{O} 157$ isolated from humans, cattle, swine, and food. Appl Environ Microbiol, 2002; 68: 576.

Sheng, H., Knecht, H.J., Kudva, I.T., and Hovde, C.J. Application of bacteriophages to control intestinal Escherichia coli O157:H7 levels in ruminants. Appl Environ Microbiol, 2006; 72: 53595366.

Stevens MP, van Diemen PM, Dziva F, Jones PW, Wallis TS. Options for the control of enterohaemorrhagic Escherichia coli in ruminants. Microbiology, 2002; 148: 3767-3778.

Tanji Y, Shimada T, Fukudomi H, Miyanaga K, Nakai Y, Unno $\mathrm{H}$. Therapeutic use of phage cocktail for controlling Escherichia coli O157: H7 in gastrointestinal tract of mice. J Biosci Bioeng, 2005; 100: 280-287.

Van Helvoort T. Bacteriological and physiological research styles in the early controversy on the nature of the bacteriophage phenomenon. Med Hist, 1992; 36: 243-270. 
Viazis S, Akhtar M, Feirtag J, Brabban AD, Diez-Gonzalez F. Isolation and characterization of lytic bacteriophages against enterohaemorrhagic Escherichia coli. J Appl Microbiol, 2001; 110: 13231331.

Weber-Dabrowska B, Mulczyk M, Gorski A. Bacteriophage therapy of bacterial infections: an update of our institute's experience. Arch Immunol Ther Exp, 2000; 48: 547-551.

Yoh M, Honda T. The stimulating effect of fosfomycin, an antibiotic in common use in Japan, on the production/release of verotoxin1 from enterohaemorrhagic Escherichia coli $\mathrm{O} 157: \mathrm{H} 7$ in vitro. Epidemiol Infec, 1997; 101-103.

Yoichi, M., Morita, M., Mizoguchi, K., Fischer, C.R., Unno, H., and Tanji, Y. (2004). The criterion for selecting effective phage for Escherichia coli O157:H7 control. Biochem Eng J, 2004; 19: 221-227.

\section{How to cite this article:}

Ghasemian A, Bavand M, Moradpour Z. A broad-host range coliphage against a clinically isolated E. coli O157: isolation and characterization. J App Pharm Sci, 2017; 7 (03): 123-128. 